Summer 2016

\title{
Living with a Spinal Cord Stimulator
}

\author{
Teresita DeVera, MSN, CRNP \\ Thomas Jefferson University \\ Carol A. Blyzniuk BSN, RN \\ Thomas Jefferson University
}

Follow this and additional works at: https://jdc.jefferson.edu/jhnj

\section{Let us know how access to this document benefits you}

\section{Recommended Citation}

DeVera, MSN, CRNP, Teresita and Blyzniuk, Carol A. BSN, RN (2016) "Living with a Spinal Cord Stimulator," JHN Journal: Vol. 11 : Iss. 2 , Article 3.

DOI: https://doi.org/10.29046/JHNJ.011.2.003

Available at: https://jdc.jefferson.edu/jhnj/vol11/iss2/3

This Article is brought to you for free and open access by the Jefferson Digital Commons. The Jefferson Digital Commons is a service of Thomas Jefferson University's Center for Teaching and Learning (CTL). The Commons is a showcase for Jefferson books and journals, peer-reviewed scholarly publications, unique historical collections from the University archives, and teaching tools. The Jefferson Digital Commons allows researchers and interested readers anywhere in the world to learn about and keep up to date with Jefferson scholarship. This article has been accepted for inclusion in JHN Journal by an authorized administrator of the Jefferson Digital Commons. For more information, please contact: JeffersonDigitalCommons@jefferson.edu. 


\section{Living with a Spinal Cord Stimulator}

Teresita DeVera, MSN, CRNP; Carol Blyzniuk, BSN, RN

Department of Neurological Surgery, Thomas Jefferson University, Philadelphia, PA

Research has shown that approximately one in three Americans suffer from chronic pain, with an annual cost of $\$ 560$ to $\$ 635$ billion from associated healthcare costs and lost productivity (Cruz et al, 2015). Historically, physicians have attempted to manage pain by using opioid-based analgesics which include medications like oxycodone and hydrocodone. Patients commonly report that pain medication becomes less effective over time, even with dose escalations and polypharmacy. Furthermore, the consequences of long-term opioid use are numerous, including over 16,000 related deaths annually. This has driven more pain management physicians to seek alternative treatment modalities, such as spinal cord stimulation (SCS). SCS is an invasive therapy used to provide pain relief for multiple types of chronic pain diagnoses when conservative and medical therapies fail.

Spinal cord stimulation is achieved by the introduction of electrical current to the painful area providing a more pleasant sensation, replacing the painful sensation; this is done by introducing a thin flexible electrode into the epidural space, which will then be used to stimulate specific targets to treat a variety of pain disorders. SCS is the number one indication in the treatment of chronic pain despite having spinal surgery, also known as "failed back surgery syndrome" (FBSS). Prospective randomized studies in patients who are candidates for a second spine surgery have shown to do better with SCS with pain reduction, health care utilization, and crossover to additional therapies and long-term costs (Deer, 2010). SCS is also used to manage pain from chronic regional pain syndrome (CRPS), ischemic limb pain, neuropathy, and cervical or lumbar persistent radiculopathy.

The use of neuromodulation for pain relief is among the fastest growing areas of medicine, involving many diverse specialties and impacting thousands of patients with various ailments. Historically, electricity, whether as a torpedo fish or man-made electrotherapy, has been used to try and cure these ailments. The modern era of neuromodulation began in the early 1960s, first with deep brain stimulation soon followed by spinal cord stimulation. In 1965, Melzack and Wall proposed the "gate theory" which postulated that pain perception involves a gate that can be opened or closed depending on the balance between firing of small and large neural fibers (Gildenberg, 2006). This concept was tested and eventually led to the development of the first implantable stimulator in 1967, which was used to treat chronic pain with peripheral nerve stimulation. However, the Gate Theory has not been fully adequate in explaining the full complexity of SCS in neuromodulation.

SCS, as well as other implantable devices in neuromodulation, have made great advances in technology over the past 4 decades. The leads have evolved from monopolar stimulation to multi-contact lead arrays. Programming SCS has become more creative, from simple monopolar fields to complex programming options to cover multiple painful areas. The generators have evolved from large and non-rechargeable for limb pain or cumbersome radiofrequency devices with an external power sources required if you had back and limb pain to smaller internal generators that can be recharged. Patients have greater freedom to place the generator in different areas of the body, such as the buttock, chest wall, or axilla. More recently, patients now have the option to choose devices that are MRI-compatible with certain manufacturer restrictions.
Conventional SCS (or tonic stimulation) creates a paresthesia sensation overlying the patient's area of pain. More recently, SCS advancements now include highfrequency stimulation (HF10), burst stimulation, and dorsal root ganglion (DRG) stimulation. This evolution has led to greater pain relief and better patient reported outcomes. There are many benefits in choosing one form of therapy over the other; however, the goal is to choose the system that best addresses the patient's needs and will lead to a favorable outcome. From a patient's standpoint, the therapy should provide the best option of reducing pain and improving quality of life.

The SCS device consists of electrode leads, extension cable, a pulse generator, and a programmer. The leads can be percutaneous, paddle, or a hybrid of both. Percutaneous leads, placed by a pain physician, neurosurgeon or orthopedic surgeon, are introduced into the epidural space via a needle under fluoroscopic guidance, while paddle leads are generally placed by a neurosurgeon or an orthopedic surgeon via an open procedure that would involve a laminotomy or laminectomy. Prior to implantation, patients undergo a temporary trial, usually lasting anywhere from 3 to 10 days. During this trial, the clinician targets the patient's pain by inserting the leads over the appropriate level of the spinal cord. The leads are connected to an external battery back wrapped securely to the patient. The patient then monitors pain relief with usual daily activities and documents this in a diary. At the completion of the trial, the leads are removed in the office and both the clinician and the patient will discuss the patient's response to the SCS. A successful trial is determined if $>50 \%$ reduction in baseline pain is achieved. It is important that the patient establish realistic goals and expectations prior to the SCS trial and is satisfied with the results of trial prior to proceeding with 
a permanent implantation. SCS is a relatively safe procedure and reversible with implant removal. Adverse events were reported between 34\% and 38\% (Song et al, 2014). The most commonly reported complication was lead migration and/or breakage.

Published studies have shown that when used by properly selected patients, SCS therapy is successful in managing chronic pain. Kumar et al. (2008) found that in selected patients with FBSS, treatment with SCS results in pain relief sustained at 24 months and is associated with patient satisfaction and clinically significant gains in functional capacity and quality of life. The advancements in SCS have led to more patient-friendly options that do not allow the therapy to interfere with a patient's function but will allow for more flexibility. Earlier introduction of SCS in the pain management algorithm that focuses on individualized pain therapy can lead to better long-term outcomes for the patient. Ultimately, patients should be well-informed of the available options that would best suit his or her needs.

\section{REFERENCES}

1. Cruz, P., Fama, C., Roth, S., Haller, J., Wilock, M., Lange, S., \& Pilitsis, J. (2015). Predictors of spinal cord stimulation success. Neuromodulation, 18, 599-602

2. Deer, T. (2010). Spinal cord stimulation for the treatment of chronic pain. Pain Medicine News, 1-8.

3. Gildenberg, P.L. (2006). History of electrical neuromodulation for chronic pain. Pain Medicine, 7, S7-S13.

4. Song, J. J., Popescu, A., \& Bell, R.L. (2014) Present and potential use of spinal cord stimulation to control chronic pain. Pain Physician, 17, 235-246.

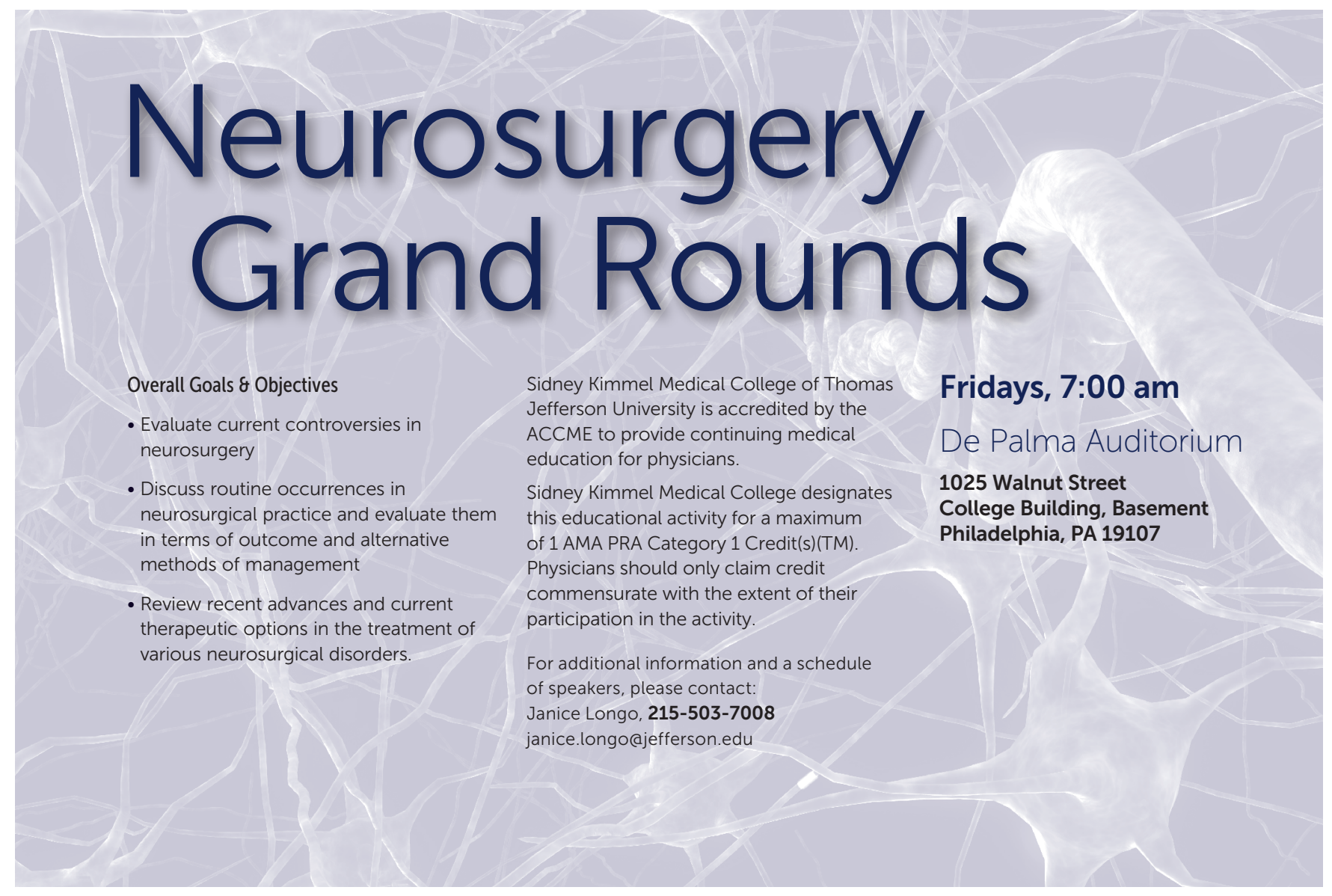

